\title{
Excess May Do Harm: Investigating the Effect of Team External Environment on External Activities in Teams
}

\author{
Cristina B. Gibson \\ University of Western Australia Business School \\ 35 Stirling Highway, Room G59 \\ Perth, WA 6009 \\ AUSTRALIA \\ phone +61405515510 \\ Email: cristina.gibson@uwa.edu.au.
}

\author{
Rebekah Dibble \\ University of San Francisco \\ 2130 Fulton Street \\ San Francisco, CA 94117 \\ Email: rdibble@usfca.edu
}

Acknowledgements: This research was funded by NSF grant \#0422676 and \#0726798 as well as support provided by the University of California, Irvine Center for Research on Information Technology in Organizations. The authors would like to acknowledge the helpful comments provided by Christopher Earley, Mark Griffin, John Mathieu, and Jone Pearce; assistance in data collection provided by Diaky Diaz, Christopher Reisdel and Bettina Wolf; and the generous time invested by all the film makers and film viewers who participated in the study.

Key words: team external activities, team environment, team effectiveness 


\title{
Excess May Do Harm: \\ Investigating the Effect of Team External Environment on External Activities in Teams
}

\begin{abstract}
We extend research on team external environment by investigating whether lack of permanence, fluid membership, and environmental volatility influence the relationship between team external activities and team effectiveness. Teams engage in external activities with clients, audiences, funding sources or other stakeholders who may receive the work of the team and/or who convey access to legitimacy and resources, and may be outside of any organization team members represent. We seek to understand whether significant external activities reach a point of diminishing returns, arguing that the utility of such activity depends on the team external environment. Our study consisted of a quantitative analysis of 140 film making teams rated by the teams and 5000 film viewers, in which we found that the relationship between team external activities and effectiveness is non-monotonic; a moderate amount of activity is associated with the highest level of effectiveness, but these effects are contingent upon the aforementioned environmental characteristics. Findings extend current theory on team external environment and external activities and have practical implications for collaborators in dynamic environments hoping to optimize their effectiveness without compromising their vision.
\end{abstract}


There is growing recognition in both theory and practice of the profound influence of the external environment on teams (Choi, 2002; Acona, Bresman \& Kaeufer, 2002; Ancona \& Bresman, 2007). This idea is not new; Homans (1950) observed that complexity and conflict in the external environment will be replicated within a group when information from the environment is imported into the group. Yet many models and frameworks for team effectiveness still focus on internal team processes, with the larger external environment that exists outside a team or the organization(s) in which a team may be embedded rarely conceptualized or operationalized with fine grained precision. In the organizational theory literature, the generic environment has been defined as all phenomena that are external to and potentially or actually influence an organization (Hawley, 1968), and it is generally agreed that to the extent that environments are more dynamic and unpredictable, organizations must spend greater resources for monitoring external conditions and responding to them, hence requiring adaptable, responsive, and reactive structures (Zenger \& Hesterly, 1997; Galunic \& Eisenhardt, 2001; Davis, Eisenhardt \& Bingham, 2007), as well as speed, flexibility, innovation, and boundaryless integration (Sinha \& Van de Ven, 2005; Palmer et al. 2001). Yet, the literature on smaller social aggregates such as teams has generally considered only an omnibus team context variable with very little attention to the specific elements of the context that might influence teams and how it might do so (Mathieu, Marks, \& Zaccaro, 2001).

Acknowledging the important interface teams have with their environment, empirical research focusing on teams suggests that externally-directed activities matter (Gladstein, 1984). Notably, Ancona's landmark series of studies (Ancona, 1987; 1990; Ancona \& Caldwell, 1988; 1992) identified a variety of categories of team external activities. For example, ambassador activities are those that are aimed at top management and involve getting resources, assessing the political situation, and getting support; task coordination activities include coordinating technical or design issues and obtaining feedback and negotiating on the product design; scout activities involve scanning for ideas and information about the competition, the market, or technology; and guard activities are aimed at avoiding release of information (Ancona \& Caldwell, 1992). Ancona and her colleagues found that ambassadorial activity was positively related to adherence to budgets and schedules, and taskcoordinator activity was positively related to innovation; while prolonged scouting activity was negatively related to performance, cohesiveness, and internal task processes (Ancona \& Caldwell, 1992). Interestingly, the amount of activity did not predict performance. 
As a team's work unfolds, changes in the external environment likely eventuate in an evolving set of preferences, needs, and requirements among customers, clients, audiences, or other stakeholders. Traditional coordination devices, such as rules or formal structure may be ineffective because tasks and external demands in such settings are too complex or uncertain to be centrally or hierarchically managed (Choi, 2002). Hence, in order to get access to the resources and legitimacy external constituents can bestow, as well as to earn their respect and maintain their business, teams must engage in external activity with them, at least to some extent. No external activity reduces opportunities to obtain valuable resources, knowledge and feedback which are critical to the effective development of products or services. Yet, too much of such external activity may mean that the team is subjected to attempts to dramatically sway or alter the product or service in a way that suits a particular external constituent, but may not be in the general best interest of the team's overall effectiveness. Likewise, the team may spend so much time responding to these external constituents that it detracts from other activities which could contribute to effectiveness, draining valuable resources. When this happens, team members may begin to feel that they are "selling out," compromising the integrity of the team and its vision, with detrimental consequences to overall effectiveness. So the key question becomes, how much team external activity is too much?

We argue that the answer to this question is likely to depend on the nature of the external team environment. In support of the importance of examining such issues, Johns (2006: 388) noted that "if we do not understand situations, we will not understand person-situation interactions". To date, specific characteristics of the external team environment and their effects on the relevance and value of externally-directed activities have not yet been empirically documented. We argue for a point of diminishing returns for external activities, and that such effects are stronger under certain environmental conditions, proposing that the less permanent the collaborative endeavor, the more fluid the structure, and the more volatile the environment, the more useful externallydirected activity is likely to be for team effectiveness, defined as the extent to which the team outputs meet the objectives of the members and stakeholders (Beng-Chong \& Ployhart, 2004; Cohen \& Bailey, 1997; Gibson, Zellmer-Bruhn \& Schwab, 2003; Hoegl, Weinkauf \& Gemuenden, 2004). We examine the proposed relationships in survey data representing 140 film making teams rated by the film makers and 5000 viewers of the films. We 
elaborate more on the context and samples in the methods section. Following the presentation of our findings we conclude with implications of our findings for theory and practice.

\section{The (Increasingly) Complex Nature of Teaming}

In much of the prior research teams were groups of individuals working interdependently, with clear boundaries, clearly defined authority, and membership stability (Hackman, 2002; Cohen \& Bailey, 1997). However, Ancona, Bresman, \& Kauefer (2002) distinguish between "x-teams" and traditional teams, with xteams set apart from traditional teams due to shifting boundaries and roles within the team, as well as the extent of activity beyond the team boundary. We note that increasingly, teams are characterized by these features, and also by increased environmental volatility due to a lack of organizational embeddedness. It is now often the case that team members each represent entirely different organizations, or they may be independent contributors or contractors with no organizational affiliation at all, anticipating only short term collaboration within a very loose structure.

Consider, for example, the joint effort of non-profit leaders, city planning officials, contractors, building materials suppliers, and volunteer builders to construct housing for needy families; the combination of medical personnel, law enforcement officers, government officials, transportation specialists, technology experts, humanitarian volunteers, and representatives of non-profit relief organizations to relieve victims of a natural disaster; a merger of the expertise of actors, musicians, electrical technicians, writers, and financiers for the production of a documentary film; or the combination of economic scholars, government officials, corporate witnesses, and attorneys working together to prosecute an organization for the breach of an antitrust law. This type of work occurs outside the boundaries of a single organization, which may house entire departments responsible for documenting challenges and implementing and routinizing solutions, such as knowledge management systems, training departments, and organizational development specialists. Teams such as these are formed for many reasons. They can bring together the best minds, skills, and knowledge, without heavy administrative or relocation costs. Participants bring with them local knowledge, skills, resources, and connections that become important assets. As a result, such teams are not limited to any given industry or project type. They may occur in settings as diverse as new product development in the pharmaceutical industry and the information technology domain, in delivery of services in the travel and hospitality industry, in 
humanitarian aid efforts, professional services, peace keeping forces, educational services, emergency healthcare, scientific research, and training and development efforts. Thus, there is a need to understand critical externally oriented activities in teams that are less permanent, more fluid, and less organizationally bound, and hence more complex and confronted with greater uncertainty, than teams of the past.

To summarize, external activities can refer to: (1) a team inside one organization interacting with other individuals or other teams inside that organization, (2) a team inside one organization interacting with others both within and outside that organization, (3) a team with members from multiple organizations, but initiated and supported within an organizational context, interacting with others both within and outside that organization or (4) a team with members who have no organizational affiliation, interacting with others outside the team. Most of the attention to external activities has focused on (1) and (2). Early conceptual work acknowledged that in response to environmental challenges, organizations sometimes call upon teams to provide links to customers, suppliers, or competitors outside the firm (Clark \& Fujimoto, 1987; von Hippel, 1990; Colman \& Bexton, 1975; Ancona,1988), and recent comparative case studies (e.g., Ancona and Caldwell, 2000; Ancona and Bresman, 2007) do address scenario (3), in which teams include members from multiple organizations, and hence members are engaging in activities which are outside of a single organization. For example, in one case study ("Netgen") described by Ancona and Bresman (2007:8) the team made use of its ties to other people, both inside and outside the firm: “...their links to top management, customers, competitors, and technologies enabled them to link toplevel strategy with knowledge and ideas from the ground.” But to our knowledge, no large scale empirical work has addressed scenario (4), which incorporates activities that are outside of any organization a team member is affiliated with, or teams in which most (or all) of the members lack organizational affiliation, and hence are subjected to greater uncertainty and complexity.

Drawing on prior research (Ancona and Caldwell, 1992; Bresman, 2010; Choi, 2002; Gibson \& Dibble, 2008), we define external activities as those that are directed toward the team's environment to manage its relationships with external actors. Recognizing the highly varied nature of team membership today that we outlined above, we expand the focus in prior research to include not just activities involving other units within organizations represented by team members, but also activities conducted with suppliers, funding and regulatory bodies such as government agencies, clients, customers, political parties, and the general public. Therefore, like 
others (Gibson \& Dibble, 2008; Choi, 2002), our definition encompasses a broad range of team activities, including both superficial external interactions, such as environmental scanning, repositioning to carve out a new niche, or redefining the constituents, stakeholders, and end users; as well as more intensive interactions with external constituents which might include shifting the product or service to maintain alignment with the external environment, or altering the time frame, production schedule, or delivery schedule to better fit the demands of the external environment.

In contrast, when we refer to internal activities, the focus is on various intra-group processes occurring within the group boundary, such as forming and enforcing group norms, communication among members, the use of internal resources, and group decision-making processes (Dibble, 2010; Choi, 2002). For example, focusing primarily on team internal processes, Okhuysen (2001) describes clusters of self-imposed interruptions and internal adaptations in teams; Cannon-Bowers et al. (1995) and Marks et al. (2000) examine team adaptation as reallocation of internal resources in response to change in the environment; and the work of Moon et al. (2004) focuses on internal structural adaptations and their interaction with members' cognitive ability and internal team coordination.

\section{OUTCOMES OF TEAM EXTERNAL ACTIVITY}

Having established the nature of teams and activities in focus here, we next examine how these activities might be related to team effectiveness. It makes intuitive sense that external activities contribute to the overall effectiveness of teams. Further, it has been found that teams that engage in activity with their external constituents are more likely to produce outputs that meet objectives and are rated favorably by stakeholders (e.g., Ancona, 1990). Early research by Katz and Tushman (1979) also found that in research-intensive R\&D projects, there is a positive relationship between external problem-solving communication and project performance.

Indeed in their meta-analysis of fifteen team-level predictors of innovation spanning three decades of research, Hulsheger et al. (2009) found external communication (average corrected correlation=.475) and vision (average corrected correlation $=.480$ ) and to be the strongest predictors.

Consider the case of documentary film makers producing a film about a humanitarian effort to change the plight of the physically disabled in Africa. In many societies, the physically disabled are either abused or abandoned and left to perish. This film chronicles new hope in caring for, educating, and employing the 
physically disabled, brought about by a visionary African citizen who himself is disabled. While making this film, the film makers faced frightening political changes, in terms of military unrest and regime changes. They also faced ever changing financial resources, with some sources of funding suddenly drying up, necessitating primarily self-financing. They faced an unpredictable, novel and under-developed infrastructure, hindering their ability to travel to, and film in, certain locations. Finally, they faced shifting time pressure from several constituents, resulting in the need to make the film in a specific window in order for it to have the greatest impact. The film makers engaged in substantial external activity with constituents outside the film making team in order to meet the challenges in their environment. Yet, they stayed true to much of their original intent and their completed film is a beautiful, heartrending work of art that audiences report increased their awareness and inspired them to get involved to help the cause. Such positive outcomes are a testament to the film makers' abilities to find the optimal level of activity directed at meeting the dynamic needs of external constituents.

Yet, at the team level, a great deal of previous research suggests that the relationship is not simple, positive and linear, but rather external team activities may constitute trade offs in attention, time, and effort, and may interfere with the development of effective internal team operations. The boundary-spanning literature indicates that groups can be underbounded, with many external ties but an inability to coalesce and motivate members to put together their knowledge, or overbounded, having high internal loyalty but an inability to reach out to the external environment (Sherif, 1966; Alderfer, 1976). Showing additional evidence for a complex effect of external activities on effectiveness, Ancona (1990) found that for teams engaged in informing or parading, cohesion and clarity of roles and goals eventually gave way to internal dissension as they failed to have productive interaction with the external environment.

More recently, Tucker, Nembhard and Edmondson (2007) found that the degree to which neonatal intensive care units (NICUs) engaged in externally focused "learn what" practices (e.g., distribution of research articles, conference calls with other NICUs, site visits to other NICUs) was unrelated to implementation success, while internally-focused "learn how" practices such as internal problem solving, were related to implementation success. Investigating sales teams in a management consulting firm, Haas and Hansen (2005) found that teams derived different levels of value from obtaining and using electronic documents and advice from colleagues outside the team, but still inside the firm. For example, it was only inexperienced teams that benefited from such 
knowledge. Wong (2004) also found complex effects for externally-oriented knowledge activities, including acquiring, sharing and combining knowledge with individuals outside the group, which she referred to as "distal learning." Both local learning (interpersonal knowledge acquisition, sharing and combination with members of the same group) and distal learning were positively related to group efficiency and group innovativeness, but distal learning was negatively related with local learning, suggesting there are performance trade-offs to engaging in either only local or distal learning.

Choi (2002) argued that internal and external activities compete against each other, each requiring team resources which are limited. Yet, he acknowledged that internal and external activities may reinforce each other and thus maintain a synergistic relationship, providing the example of high performance as a result of effective external activities infusing feelings of pride and collective efficacy among team members that enhances the quality of internal dynamics. Showing support for this, Bresman (2010) investigated external learning-related activities in 62 pharmaceutical teams, comparing vicarious learning activities (that allow a team to learn from external experienced others about its task), contextual learning (that allow a team to learn from external sources about its context), and internal learning activities (asking questions, seeking feedback, sharing information, experimenting, talking about errors, and other activities that allow a team to learn based on the experiences of its members). He found that vicarious learning activities were more strongly associated with performance when teams engaged in more internal learning activities, that vicarious learning activities in the absence of sufficient amounts of internal learning activities hurt performance, and that the positive performance associated with contextual learning activities, by contrast, was unaffected by the level of internal learning activities.

Activities which are focused inside the team help to produce alignment, while those that are externally focused are often heralded as critical for adaptability (Ancona and Bresman, 2007; Choi, 2002), because such external activities provide not only cues regarding the need for adaptation, but also knowledge regarding how to do so in a way that allows the team to meet the needs of clients, stakeholders and other constituents. Although much of it is focused on the business unit or organizational level of analysis, recent research provides clues to the means by which simultaneous alignment and adaptability are achieved. For example, Adler, Goldoftas, and Levine (1999) examined changeover events at Toyota's NUMMI (New United Motor Manufacturing Inc.) automobile assembly plant and found that mechanisms such as meta routines, enrichment, switching, and 
partitioning shifted the typical trade-off between efficiency and flexibility. Likewise, Gibson and Birkinshaw (2004) found evidence in a multi-industry sample of over 4000 employees in 41 business units that adaptability the ability to move quickly towards new opportunities, to adjust to volatile markets, and to avoid complacency -must be paired with the capability for alignment - a clear sense of how value is being created in the short term, and how activities should be coordinated and streamlined to deliver that value. The simultaneous achievement of alignment and adaptability, which they referred to as contextual ambidexterity, mediated the relationship between features of the organizational context and subsequent performance. Thus in their study, successful business units were not just innovative and proactive in responding to their environment; they were also very good at aligning their existing internal capabilities in order to develop cohesive strategy. Similarly, responsive behavior can be achieved in turbulent environments by helping people to reduce role stress through clarifying their responsibilities and providing them with guidance in their work (Adler \& Borys, 1996). Evidence of this was obtained by Bigley and Roberts (2001) in their qualitative analysis of a fire department. They found that certain internal structural mechanisms, as well as rules and routines, established along side flexible switching of roles, migration of authority, and cognition management techniques, enabled the department to attain remarkable reliability under extreme environmental uncertainty and instability.

Likewise, we anticipate that because they are conduits for knowledge, resources, social support, and legitimacy necessary for adaptation, external activities in teams contribute to effectiveness because they compliment internally-focused activities that create alignment, but only up to a point. External activities require substantial effort and time, and as a result, likely represent trade-offs in terms of resources and attention that can be directed both internally to team processes, and also directly to the task at hand. Activities may initially be functional from the point of view of satisfying external constituents, but may prove difficult to sustain, may create challenges to functioning inside the team, or may result in trade-offs in more distal outcomes that eventually out-weigh any short term, proximal functionality. External activities may also be particularistic, satisfying a limited set of external constituents in that moment, while failing to accomplish broader and longer term objectives. Therefore, beyond moderate levels of external activity, extreme amounts of externally-directed activity may actually have a detrimental effect on the overall effectiveness of a team because they become disorienting and so destabilizing as to create ambiguity and anxiety, and may result in collaborators working at 
cross-purposes or with redundant effort, reducing overall coordination. Bresman (2010) mentions the possibility of harmful external activities in teams as an important avenue for future research, although he did not find direct evidence of such a phenomenon in his study. Yet, it is possible to envision that excessive activity may cause the team to lose its sense of consistency and focused effort, potentially compromising the original intent, such as a creative vision for a product or service, particularly if the team engages in external activity without considering internal alignment. This type of unbalanced external activity may result in "selling out", compromising the team's originally conceived course of action to the detriment of its overall performance. Perhaps only a particular constituent, or a limited set of constituents are pleased, but the general effect of the extreme levels of external activity is dysfunctional. The intent, objectives, and potential impact of the team are diminished and diluted through myriad comprehensive changes to accommodate external constituents. Hence, we propose:

Hypothesis 1 (H1): External activity will demonstrate a non-monotonic (inverted U-shape) relationship with effectiveness, such that moderate external activity will be associated with the highest level of effectiveness, and very little or very extreme external activity will be associated with lower levels of effectiveness.

\section{MODERATORS OF THE OUTCOMES OF EXTERNAL ACTIVITY}

In this section, we address the question of how aspects of the team environment change the nature of the relationship between external activities and effectiveness. Prior research has emphasized that external activities can distract teams from processes inside the team which need to be managed. While this logic offers part of the explanation regarding a point of diminishing returns for external activities (i.e., external activities will cease to be useful when they begin to drain resources needed for internal activities), it doesn't take into consideration the role of key features of the team's working environment which may influence the usefulness of external activities. Here, we argue that external activities are more useful, productive and necessary when there is a lack of permanence on the team, high fluidity of member roles, and volatility in the external environment.

\section{Lack of Permanence}

First, in terms of lack of permanence, many participants in teams come together on a one-time basis, without anticipating continued interaction. There may be no consistent "core" set of members, as there are in the x-teams described by Ancona and colleagues (2002). Ancona et al. (2002) characterize core members (as opposed to "operational members" and "outer-net members") as those who are often present when the team's work 
begins, carry the team's history and identity, coordinate multiple aspects of the team, create team strategy, and make critical team decisions. Based on their long-standing experience with the team they have the necessary understanding of why early decisions were made and they appreciate the rationale behind current decisions and structures. Teams without any clear "core" are increasingly common in those teams set up for process improvement which work across geographies and in teams whose project work necessitates an ever changing membership.

Temporary teams likely find it difficult to establish stable routines for coping with the external environment (Katz, 1982). When a team has been in existence for years, external constituents anticipate its ongoing presence, allowing for patterns of behavior to be established in advance. Expectations, norms, and pathways for information resources are likely institutionalized to the extent that anyone who joins or works with the team knows how it can best get work done. As a result, significant "mining for resources" is not required, and the external activity is likely to be programmatic and routine. This reduces the extent to which extensive additional external activity will produce performance gains. Interestingly, in their meta-analysis of team-level predictors of innovation spanning three decades of research, Hulsheger et al. (2009) found no significant relationship between team longevity and innovation. We suspect this may be because rather than a direct effect on team outcomes, longevity interacts with team behaviors (such as external activities) to change the strength of the effect of those behaviors on team outcomes.

Hypothesis 2(H2): Lack of permanence will increase the association between external activity and effectiveness.

\section{Fluidity of Roles}

Second, participants may have periods of intensely interdependent interaction, but may otherwise consist of quite independent actors, and there may be many changes in the roles represented and the role incumbents, unlike the institutionalized role structures that provide stability in projects such as those described by Bechky (2006). Teams in many different industries may involve a set-up period during which some participants may not be formally on board yet while they are finishing work on a different effort, but they may already be in contact with participants on a new endeavor and may be involved in important decisions about that work. During this process, participants may float on and off the effort, working only on an as needed sporadic basis. Additionally, 
there is often a closing-down period, when some participants have already left the team to become involved in their next project, while still completing the current one.

When membership in a team is fleeting, and members who haven't worked together begin a project, they are likely not to ask one another about who knows what; instead, they are likely to ask about what is known about the situation and about the actions taken thus far (Dyer and Shafer 2003, Hale et al. 2005). Using the example of emergency response groups, Majchrzak et al. (2007) suggest that under such conditions, coordination that develops for the team centers not around people, but on action-based scenarios that either have been or might be carried out; these scenarios include decisions, actions, knowledge, events, and feedback (Vera \& Crossan 2005). The scenarios are not scripts, because they do not define the roles that people play; instead, the scenarios are patterns of actions strung together to be matched with events (Dyer and Shafer, 2003). Thus, when expertise is constantly changing, the focus of the team's efforts may not be on agreeing who has expertise in a task-related topic, rather more significant performance benefits are realized by constantly scanning the environment to locate knowledge and other resources outside the team (Majcharzak et al., 2007). Such efforts are likely to yield higher returns in teams with fluid membership than in those teams that have stable membership.

Further, in teams whose roles are rarely occupied on a consistent basis by the same person, establishing efficient conduits for knowledge, social support, and legitimacy is challenging. Such resources are often provided in long standing relationships with external constituents, and when a different person occupies a given role each time the external connection is made, the resources are less likely to be forthcoming, requiring substantial interaction with the external constituents in order to procure. When the team is comprised of stable roles and the same individuals are occupying those roles over time, long term relationships can be developed with external constituents, and trust and legitimacy flow more effortlessly, potentially requiring less external activity to procure, reducing the value-added of additional external activity intended to enhance effectiveness.

Hypothesis 3(H3): Role fluidity will increase the association between external activity and effectiveness.

\section{Environmental Volatility}


Third, the work of many teams is characterized by environmental volatility, which is in and of itself multidimensional. Davis, Eisenhardt and Bingham (2009) highlight four dimensions, including velocity, complexity, ambiguity, and unpredictability. Here, we suggest that as it pertains to external activities in teams, environmental volatility is primarily a result of a lack of organizational embeddedness, which in turn results in complexity defined as a diversity of environmental features that must be addressed by the participants (Dess \& Beard, 1984; Mathieu, Marks, \& Zaccaro, 2001), as well as uncertainty, defined as unpredictability of the environment and the extent to which it is possible to forecast challenges in advance (Waller, 1999; Sutcliffe, 1994; Milliken, 1987). The need for examination of the moderating effect of environmental volatility on the relationship between team processes and performance has been highlighted by Bunderson and Sutcliffe (2003). Specifically, they called for future research examining the role of environmental uncertainty on the relationship between a team's learning orientation and an organization's performance. However, their focus was on teams embedded in a single organization, while we include teams which are not embedded in any overarching organization, that may experience even greater exposure to changing environmental conditions, as they may be without the types of human, financial, or technological resources required to effectively buffer themselves from the complexity and uncertainty of their external environments (Milliken, 1987).

Dayan and Basarir (2010) provided evidence that environmental turbulence, defined as frequent, unpredictable market and/or technological changes, moderated the relationship of team reflexivity with market success of new products, such that the relationship was stronger the greater the turbulence. They reasoned this was the case because turbulence makes it difficult to forecast accurately and creates risk and uncertainty in the new product development process, which required greater activity inside the team aimed at coping with the behavior. This evidence is suggestive of the moderating effects we propose here, but the authors focus on internal team activities and teams embedded in a single organization.

Additional evidence for the moderating effect of environment comes from work by contingency theorists. Although they focus on the work unit level of analysis (defined as a supervisor and the personnel reporting to that supervisor), these scholars have accumulated evidence that organic strategies (i.e., in which there is more discretion and less standardization, allowing the unit to engage in a greater range of external activity) are effective only under certain circumstances. Specifically, an organic design has been found to be most 
effective when units operate in a context of high uncertainty (e.g., Van de Ven \& Ferry, 1980), because such designs are less prone to information saturation (Gresov, 1989). That is, because uncertainty imposes pressures to process more information and to create the capacity to process this information, more organic structures are necessary. At the same time, when units operate in a context in which there are few coordination requirements across units (low context dependence), then prior research shows that organic strategies work less well (Ito and Peterson, 1986). This work indicates that it is not simply the case that the more "organic" the better, there may be diminishing returns of certain activities within the unit (or team). Consistent with Gresov (1989), we argue that it is in situations of high uncertainty and low context dependence (what we refer to as volatility or lack of embeddedness) that the situation becomes precarious. Gresov's (1989) investigation of 529 work units showed that when task uncertainty was low and the units were embedded in an organizational context, units could remain insular and prescribed patterns of behavior resulted in higher performance. When these conditions did not exist, "misfit" resulted and the optimal behaviors were less clear.

Finally, if the team is at least to some extent embedded in an organization (or contains a majority of members from one organization, as opposed to each member representing a different organization or having no organizational affiliation), there is less complexity and uncertainty to manage. External activity may not be necessary in order to improve effectiveness. Both complexity (diversity of environmental features that must be addressed, Dess \& Beard, 1984) and uncertainty (inability to forecast in advance what performance conditions will exist, Waller, 1999; Milliken, 1987), make it difficult to determine how best to interact with external constituents. Choi (2002) also suggested that a team may need to perform greater external activities when it deals with many differentiated external actors who are unpredictable and demanding, as compared to a small number of stable external actors, and Milliken (1987) argued that boundary spanning and information acquisition are particularly important when there is a lack of understanding of optimal responses to uncertain environmental conditions, but empirical evidence has yet to provide support for this set of ideas. Complexity suggests the possibility that multiple, different constituent needs exist, while uncertainty suggests that their exact needs and requirements are unknown. High levels of both will likely make it all the more critical that the team interact intensively with external constituents in order to be effective: 
Hypothesis 4 (H4): Environmental volatility will increase the association between external activity and effectiveness.

\section{METHODS}

We focused on the film industry because film-making teams differ on the three characteristics of the environment we focus on here (permanence, fluidity, and environmental volatility). Further, film making provides an apt example of a collaborative dynamic, in the sense that many film-making teams are conglomerations of various talents (e.g., directors, cinematographers, writers, actors, managers, financiers, volunteers, activists) who come together for the purpose of creating a specific product (a film), who collaborate intensely for a specific period of time, and then disband, only to find themselves joining a new collaborative endeavor at the onset of their next production. We focus specifically on humanitarian documentary film making, which even more than the commercial film industry, contains teams characterized by lack of permanence, fluidity and volatility. That is, such film making often takes place in environments that subject film makers to volatile circumstances, spanning a variety of international contexts, bridging for-profit and not-for-profit domains, and requiring governmental and institutional cooperation, making the setting an ideal context to examine external activity. Documentary film production in particular has become organized more globally because of the availability of low-cost facilities and crews outside the major film production areas and because of a scarcity in local skills and talents (Wasko, 1994). Studying such teams provides an opportunity to identify issues associated with the management of leading edge new forms of organizing (Palmer et al. 2001; Cattani \& Ferriani, 2008).

We began by conducting structured interviews with producers, directors, actors, screenwriters, union officials, film commissioners, guild directors, and film viewers across four regions of the world representing different stages of film industry development (New Zealand, the U.S., India, and France). A total of thirty four interviews, 1-3 hours in duration were conducted about a broad range of team activities, film making and films (the interview protocols appear in the appendix). The purpose of the interviews was to better understand the film context, to help develop the concept of external activities, to ensure the research questions were pertinent, and to inform the research design and survey development. Following the interviews, we collected survey data at 
documentary film festivals, which provided ready access to a variety of film-making teams, as well as to a diversity of viewers who provided independent assessments of the outcomes of films.

\section{Sample and Procedure}

We contacted directors for three festivals to obtain a list of film makers on all films to be screened at the festival and sent an invitation to each, giving film makers the option of completing the survey either in hard copy or electronic format. This resulted in usable responses from 140 film-making teams from the 195 films that were screened at the festivals, for an overall response rate of 72 percent. The films in our sample are independent humanitarian documentary films, with a focus on international human rights, children's advocacy, animal rights and environmental awareness. Using procedures similar to those used by other organizational scholars (Carson et al. 2006; Subramaniam \& Youndt, 2005) we checked for potential response bias and found no significant differences across respondents and non-respondents on key variables such as film type, box office revenues, online quality ratings provided by film viewers, and organizational embeddedness (measures described below).

We utilized an informant sampling approach (Van de Ven \& Ferry, 1980) to improve the number of teams represented and reduce the barriers to participation. An informant sampling approach recognizes that many members of a particular collaboration are qualified to provide assessment of properties they experience together and so "relies on a limited selective sample of people who are most knowledgeable of the global properties of interest" (Van de Ven \& Ferry, 1980: 72) rather than attempting to obtain input from every member of each team. Recent examples of the key informant approach include Subramaniam and Youndt's (2005) study of intellectual capital and innovation; Maitlis and Lawrence's (2007) examination of the conditions that trigger and enable sensemaking in the administration of a symphony orchestra; and Carson, Madhok and Wu's (2006) study of corporate governance in managing project development relationships.

We inquired as to the total number of people involved in making each film, and found that the average number involved (the average total team size) was 9 members. Yet, the informant sampling approach was necessary because reaching every member of the type of complex teams in focus here is impossible, as many members have only short term participation, and then move on to other projects, and contact with these participants is often lost. The total number of individuals included in the sample was 334 . Most of the films in our sample (105 films or 75\%) were represented by 2 or more participants; 35 films were represented by one 
participant. One-way analysis of variance for each study variable (with number of team members included in the sample as the independent variable) indicated that there were no significant differences based on how many film makers rated the team. In every team in the sample, we received a response from the director of the film; other roles represented include those such as the producer, editor, director of photography, and screenwriter. Where more than one film maker in a team responded to the survey, we averaged their scale scores to create a single score on each variable (justification for aggregation included below), hence the film making team is the unit of analysis.

The demographic characteristics and contextual conditions for the film-making teams varied widely. The age of the film makers in our sample ranged from 18 to 69, with a mean age of 40, and the largest segment (39 percent) falling into the 36-45 age group. Respondents were 58 percent male. Experience of the respondents also varied from 1 to 62 films, with film makers having been involved with an average of 15 films in their careers. The film making context was also diverse, with the number of locations where work was conducted on the films ranging from 2 to 12, with an average of 4 locations per collaboration. Additionally, the number of countries worked in ranged from 1 to 8 with a mean of 2 countries per film.

Our film maker survey instrument assessed over 40 topics related to collaborative processes across the entire production process (i.e., pre-production, filming, and post production), including film makers' roles in the collaboration (director, producer, editor, etc.); their goals for making the film and the extent to which these were achieved; the extent to which external challenges were experienced; the extent to which external ties were forged; their vision for the project and how this was communicated; their beliefs about their ability to be effective; their use of information technology; collaboration structures; and the degree to which external activity occurred with external constituents (the survey is available from the authors upon request). Film makers completed the instrument online just after completing the film, but before the film premiered at the festival, hence none of the films had been distributed prior to our assessments (i.e., film makers could not apply for inclusion in the film festival until they had a completed film to submit with their application, they received our survey immediately upon application to the festival).

The effectiveness of the films was rated by an independent source: film audiences who viewed the film during its opening premier. That is, we took great care to collect our outcome measures from individuals other 
than film makers themselves, in order to reduce common method bias and increase the validity of our findings. Specifically, we surveyed approximately 5000 film viewers who attended the film festivals. Viewers were asked to complete a brief voluntary survey after viewing the films at the festival, capturing their reactions to the film as well as its impact, effectiveness and quality. We received a mean of 11 film viewer responses per film, with a range of 3-90 responses. We controlled for the number of film viewers rating each film in our analysis, and found no significant variance due to number of raters. Film viewers were 56 percent women, the majority were in the 36-45 age group, had salaries of $\$ 25,000-\$ 50,000$, and had 4 year college degrees. Viewers represented diverse ethnic backgrounds and industries. Less than $5 \%$ of viewers were themselves affiliated with the film industry, nor were any of the specific viewers who rated the films considered external constituents by our film makers.

\section{Measures}

External activities. As mentioned above, we define external activities as those that are directed toward the team's environment to manage its relationships with external actors, including those involving other units within organizations represented by team members, but also activities conducted with suppliers, funding and regulatory bodies such as government agencies, clients, customers, political parties, and the general public. In our context, external constituents may include those that live in the region and are experiencing the challenges being documented in the film. They may benefit from its distribution due to the awareness it raises, but they are not involved in making the film, nor are they a member of any organization that the film making team may be affiliated with. These people are similar to customers or clients in other contexts. Another example is a funding source for the film. They don't make the film, and hence aren't part of the film making team or any organization the members are affiliated with, but often do attempt to influence it.

All participants in the film reported the extent to which the team engaged in any external activities in interaction with external constituents using four items: (1) We interacted with external constituents outside our team [i.e., suppliers, funding and regulatory bodies such as government agencies, clients, customers, political parties, or the general public] to address financial challenges (e.g., changes in funding), (2) We interacted with external constituents outside our team [i.e., suppliers, funding and regulatory bodies such as government agencies, clients, customers, political parties, or the general public] to address time-based challenges (e.g., 
increased urgency or delays), (3) We interacted with external constituents outside our team [i.e., suppliers, funding and regulatory bodies such as government agencies, clients, customers, political parties, or the general public] to address technological challenges (e.g., technical failure or new technologies to incorporate) and (4) We interacted with external constituents outside our team [i.e., suppliers, funding and regulatory bodies such as government agencies, clients, customers, political parties, or the general public] to address work force challenges (e.g., changes in access to skilled workforce) outside the team. All items were responded to using a 5-point Likert scale $(1=$ not at all; $5=$ very great extent) (alpha $=.80)$. We conducted a validity exercises for external activity which involved an independent measure by parties not involved in the films. That is, sometimes the content of a film reveals the variety of ways that film makers had interacted with external constituents. For example, they may have discussed in the film itself their interaction with those that live in the region being documented. We were interested in the extent to which viewers of the films recognized this activity, and whether such recognition was correlated with film makers' own reports of external activity. We included two items on the film viewer survey which assessed the extent to which the viewers recognized that the team had conducted external activities. Scores on these items were correlated $.35(\mathrm{p}<.05)$ with the measure of external activity we obtained from the film makers used in our tests of hypotheses, suggesting that film makers own reports of external activity coincided with film viewers' recognition of such activity.

Effectiveness. Overall effectiveness is a common outcome variable in both the team and organizational literature and is generally assessed in terms of the extent to which the outputs meet the objectives of the collaborators and constituents and are rated favorably by them (e.g., Beng-Chong \& Ployhart, 2004; Gibson, Zellmer-Bruhn \& Schwab, 2003; Hoegl, Weinkauf \& Gemuenden, 2004). Our operationalization of effectiveness includes these same basic facets, and is comparable to prior research. However, as is typical, we selected specific item wording to fit our context, based on our exploratory interviews with film makers. Film viewers who viewed the films made by the film makers at film festivals rated effectiveness using four items: (1) "will you recommend this film to others?" (2) "was this film appropriate for the target audience?" (3) "do you plan to change your behavior as a result of this film?” and (4) “overall the quality of this film was excellent" using a 5-point Likert scale $(1=$ not at all; $5=$ very great extent $)($ alpha $=.85)$. 
To address potential concern that film festival viewers are non-representative of the more general public, we assessed the external validity of our effectiveness measure by comparing ratings provided by festival film viewers to outcomes reported in the Internet Movie Database (IMDb), the internet's largest movie and television site, a source increasingly used by organizational scholars (Ferrani, et al. 2005; Cattani \& Ferriani, 2008). It is visited by over 52 million users per month and offers film makers the opportunity to provide key information about their films to the public. Film data on the site includes general information on the film (e.g., director, writers, distributors, box office details), as well as an opportunity for film viewers to anonymously rate the film online on a scale of 1 to 10 . Once 5 ratings for a film have been submitted (average number of ratings was 10), an IMDb online viewer rating is displayed, using a weighted average of all ratings received online. Approximately half (66) of the films in our data set have appeared in IMDb, and for those that do appear, ratings on our effectiveness scale (provided by film festival viewers) were highly correlated (Spearman's rho) with box office revenues $(\mathrm{r}=.80, \mathrm{p}<.01)$. An additional item rated by our film festival viewers ("Do you believe this film was new and unique?”) was also correlated (Spearman's rho) with IMDb online viewer ratings $(r=.40, \mathrm{p}<.05)$.

Moderators. Our sample and measures were selected specifically to provide variance on the three characteristics (permanence, fluidity, and environmental volatility) that we argue influence the relationship between external activity and effectiveness. Members of the film making teams rated each of these characteristics. Our measure of permanence assesses the extent to which there was a consistent core set of members or whether all collaborators had short term and varied involvement with a 3-item index. The first item was "To what extent was there a permanent core set of collaborators with ongoing collaboration?" using $1=$ not at all to $5=$ very great extent; the second item captured an overall assessment of the permanence of the team on a scale ranging from $1=$ not at all permanent to $5=$ always permanent; the third item captured the average pair wise duration of collaboration between each member of the team on this film in months (alpha $=.75$ ). We measured fluidity with a 3-item scale capturing the extent to which the team: (1) added new roles, (2) removed roles, and (3) changed which collaborators held which roles $(1=$ not at all; $5=$ very great extent) (alpha $=.82)$. Finally, we captured volatility using three items: (1) “The environment in which we worked was complex"; (2) “The environment in which we worked was unpredictable" and (3) "Collaborators represented subcontractors or vendors from different organizations" ( $1=$ not at all; $5=$ very great extent) (alpha=.88). Confirming that we 
achieved variance on these three characteristics, teams in our sample represented the full range of the scale on each variable (1.00 to 5.00). Hence, we had teams in our sample with relatively permanent membership, as well as teams with no permanent core members; we had teams in our sample with stable roles as well as teams with very high fluidity among roles, and we had teams with little volatility and those operating in highly volatile environments. This variance is due to the variety of reasons and ways in which independent documentary film making teams are formed, composed, operated, and funded. Some revolve around a single novice film maker who enlists the help of technicians on an improvisational basis, driven by availability of skills and costs. Others are embedded within a larger, more stable structure, such as a film commission, which supplies some of the talent and resources, resulting in individuals working together on multiple projects and having more stable roles.

We conducted an external validity check of the volatility scale to provide additional evidence that we were capturing a lack of organizational embeddedness. An independent rater (blind to the hypotheses) examined IMDb archival records indicating organizational affiliations (e.g., production companies, funding sources, distribution companies) and rated each team using a 4-point scale where $0=$ no organizational affiliations reported, $1=$ small, limited-scope organizational affiliation, $2=$ moderate size limited-scope organizational affiliation (e.g., association with a marketing agency), to 3= large, broad-scale organizational affiliation (e.g., association with a studio which might provide talent, funding, and marketing). This rating was negatively correlated with our scale $(\mathrm{r}=-.38, \mathrm{p}<.01)$, indicating that when there was no organizational affiliation, or only a small limited-scope organizational affiliation, respondents reported high volatility using our scale (and when the collaborative endeavor was embedded in a large, broad scope organization context, low volatility was reported).

Control variables. We controlled for the size of the team (i.e., number of members) because it may be more difficult to coordinate and implement external activities in larger teams. We also controlled for the number of people rating each film, given there was substantial variance across films on this variable.

\section{Aggregation}

Each of the variables utilized in our research is a team-level construct. However, to quantify each of these measures at the team level of analysis, data was collected from individuals (film makers rated the independent variable and moderator variables; viewers provided the effectiveness ratings) and aggregated to represent the team. In order to justify this approach, we must be able to demonstrate sufficient agreement within 
teams and differences between them (Klein \& Kozlowski, 2000). We conducted three separate analyses in this regard. First, an $r_{w g}$ score measuring inter-rater agreement was calculated for each construct. The mean $r_{w g}$ was .94 for external activity, .77 for effectiveness, .83 for permanence, .95 for fluidity, and .88 for volatility.

The second and third analyses were computations of intraclass correlation coefficients (ICC 1 and 2 scores) which were calculated using one-way ANOVA output with the film as the independent variable and the scale scores for the measures as the dependent variables. Positive ICC(1) values and significant corresponding Fvalues indicate the appropriateness of aggregating individual scores to the team level (Bliese, 2000; Kenny \& LaVoie, 1985). These conditions were met. For external activity, $\operatorname{ICC}(1)=.97, \operatorname{ICC}(2)=.98, \mathrm{~F}=60.45, \mathrm{p}<.001$; for effectiveness, $\operatorname{ICC}(1)=.59, \operatorname{ICC}(2)=.90, \mathrm{~F}=9.53, \mathrm{p}<.001$; for permanence, $\operatorname{ICC}(1)=.78, \operatorname{ICC}(2)=.88, \mathrm{~F}=8.00$, $\mathrm{p}<.01$; for fluidity $\operatorname{ICC}(1)=.71, \operatorname{ICC}(2)=.83, \mathrm{~F}=5.98, \mathrm{p}<.05$; and for volatility, $\operatorname{ICC}(1)=.67, \operatorname{ICC}(2)=.80, \mathrm{~F}=5.04$, $\mathrm{p}<.001$.

\section{RESULTS}

The means, standard deviations, and intercorrelations of the variables appear in Table 1. We ran an OLS regression model to test $\mathrm{H} 1$ regarding the relationship between external activity and effectiveness. In the first step, we entered the controls as well as the term for the direct linear effect of external activity. The controls failed to predict significant variance in team effectiveness, indicating that in the context of documentary film making, neither the size of the team, nor the number of viewers rating it, influenced the viewers' assessments. Adding the quadratic term in the second step (beta $=-1.13, \mathrm{p}<.01)$ resulted in a significant change in $\mathrm{r}$-square $\left(\Delta \mathrm{R}^{2}=.05\right.$, $\Delta \mathrm{F}=7.61, \mathrm{p}<.01$ ), providing evidence for the non-monotonic effect predicted in H1 (Pedhazur \& Schmelkin, 1991) (see Table 2). In the second step the overall R-square was .07 $(\mathrm{F}(4,139)=2.74, \mathrm{p}<.05)$. Further, graphing the relationship between external activity and overall effectiveness demonstrated the predicted inverted U-shape relationship. Teams were most effective when external activity approached the mean.

We tested H2 - H4 regarding the moderating effect of lack of permanence, fluidity, and volatility on the relationship between external activity and effectiveness in subsequent steps of the model in Table 2 following suggestions provided by Dawson and Richter (2006). In Step 3, we added the direct linear effect of each of the proposed moderators. This failed to result in a significant change in R-square. In step 4, we added multiplicative interaction terms representing the interaction of the quadratic term for external activity $\mathrm{x}$ lack of permanence, the 
quadratic term for external activity x fluidity, and the quadratic term for external activity x volatility. Doing so resulted in a significant change in $\mathrm{r}$-square $\left(\Delta \mathrm{R}^{2}=.14, \Delta \mathrm{F}=8.25, \mathrm{p}<.001\right)$, and the beta coefficients for each of the interaction terms were significant, providing evidence for the moderating effects proposed in $\mathrm{H} 2-\mathrm{H} 4$. In the final step the overall R-square was .26 $(\mathrm{F}(10,139)=4.59, \mathrm{p}<.001)$.

We also ran a model (4a) which included the products of the linear term and moderator terms (external activity $\mathrm{x}$ lack of permanence, external activity $\mathrm{x}$ fluidity, external activity $\mathrm{x}$ volatility) prior to entering the products of the polynomial term and the moderator terms (external activity squared $\mathrm{x}$ lack of permanence, external activity squared $x$ fluidity, external activity squared x volatility). The change in R-square remained statistically significant on the final step $\left(\Delta \mathrm{R}^{2}=.06, \Delta \mathrm{F}=3.59, \mathrm{p}<.01\right)$, and overall $\mathrm{R}$-square was .29 $(\mathrm{F}(13,139)=3.89, \mathrm{p}<.001)$, although only one of the interactions between polynomial term and moderator remained statistically significant (fluidity). However, none of the linear term x moderator terms were statistically significant in this alternate model. Aiken and West (1991: 109) noted that it is appropriate to eliminate nonsignificant lower-order terms when interpreting hypothesized effects and Ganzach (1994: 245) argued that curvilinear effects should be given priority over interaction effects. Because these linear interaction effects were not hypothesized, were not significant on their own, and were highly correlated with the polynomial terms we gave priority to the results of Model 4.

Next, we ran a series of post hoc analyses and plots (See Figure 1a to 1c) to reveal the nature of the moderating effects as recommended by Aiken and West (1991) and Dawson and Richter (2006). First we divided the sample into a subset with values one standard deviation above the mean on permanence $(\mathrm{n}=34)$ and a subset with values one standard deviation below the mean on permanence $(n=26)$. Next, we repeated the analyses depicted in steps 1 and 2 of Table 2 in each of the subsets of the sample. When permanence was high (i.e., no lack of permanence), the relationship between external activity and effectiveness was negative and linear indicating that external activity reduces effectiveness (beta $=-.39, \mathrm{p}<.01$ ), and there was no evidence of a nonmonotonic effect (entering the quadratic term in the second step failed to result in a significant change in Rsquare, and the coefficient for the quadratic term was not significant). However, for the subset of the sample one standard deviation below the mean on permanence (i.e., those that lack permanence), entering the quadratic term in the second step resulted in a significant change in $\mathrm{R}$-square $\left(\Delta \mathrm{R}^{2}=.12, \Delta \mathrm{F}=3.32, \mathrm{p}<.05\right)$, and the coefficient 
for the quadratic term was significant (beta $=-1.87, \mathrm{p}<.05$ ). Plotting the relationships demonstrated the predicted inverted U-shape relationship for the teams that lacked permanence; they were most effective when external activity approached the mean.

We repeated this analysis for fluidity and for volatility. For the subset of the sample with values one standard deviation below the mean on fluidity $(n=26)$, there was no relationship between external activity and effectiveness. However, for the subset of the sample with values one standard deviation above the mean on fluidity ( $\mathrm{n}=28)$, entering the quadratic term in the second step resulted in a significant change in $\mathrm{R}$-square $\left(\Delta \mathrm{R}^{2}=\right.$ $.28, \Delta \mathrm{F}=18.33, \mathrm{p}<.001$ ), and the coefficient for the quadratic term was significant (beta $=-2.70, \mathrm{p}<.001$ ). Plotting the relationships demonstrated the predicted inverted U-shape relationship for teams with high fluidity; they were most effective when external activity approached the mean.

Likewise, for the subset of the sample one standard deviation below the mean on volatility $(\mathrm{n}=21)$, there was no relationship between external activity and effectiveness. However, for the subset of the sample with values one standard deviation above the mean on volatility $(n=23)$, entering the quadratic term in the second step resulted in a significant change in $\mathrm{R}$-square $\left(\Delta \mathrm{R}^{2}=.28, \Delta \mathrm{F}=9.56, \mathrm{p}<.01\right)$, and the coefficient for the quadratic term was significant (beta $=-2.49, \mathrm{p}<.01$ ). Plotting the relationships demonstrated the predicted inverted $\mathrm{U}$ shape relationship for teams with high volatility; they were most effective when external activity approached the mean.

Insert Table 2 and Figure 1a-1c about here

\section{Post Hoc Analyses of Alternative Explanations}

Recent work indicates the potential role played by operating in diverse socio-economic contexts $(\mathrm{Xu}$, Pan, \& Beamish, 2004), virtuality (Gibson \& Gibbs, 2006), task characteristics (e.g., Wageman, 1995), and shared past experience (Taylor \& Greve, 2006) in teams. To investigate the possibility that these facets of teaming may also represent important boundary conditions for our theory of external activity, we conducted a series of additional hierarchical regression models in which we entered them as moderators, substituting them for our three core characteristics of context. 
First, we investigated the regulative institutional context of the primary film location $(\mathrm{Xu}, \mathrm{Pan} \&$ Beamish, 2004) capturing the extent to which rules and laws ensure order in a society, including indicators such as anti-trust policy and the effectiveness of the legal system, reasoning that those locations with more regulative controls would be easier to adjust to and contribute to overall effectiveness. Next, we investigated the normative institutional context for the primary location (Xu, Pan, \& Beamish, 2004), capturing the degree to which the values and norms that govern people's behavior facilitate organizational effectiveness, including indicators that assess product design capability; attention to customer satisfaction; training; willingness to delegate authority; compensation policies linked with pay; low nepotism; and board effectiveness, again reasoning that a context with effective norms could facilitate activity and effectiveness.

We also investigated electronic reliance, measured by asking film makers the extent to which they were reliant on electronic communication (e.g., email) to accomplish their film using a 5 -point Likert scale $(1=$ not at all; 5=very great extent) (Gibson \& Gibbs, 2006) and geographic dispersion in terms of the spatial distance among members, calculated as the pair-wise geodesic distances between film locations, weighted by the number of collaborators working at each site, based on a matrix of all possible, non-redundant, member-to-member connections (O’Leary \& Cummings, 2007).

Next, in terms of traditional task characteristics, we investigated task interdependence, measured with four items (alpha $=.77)$ capturing the extent to which the collaborators were dependent on others for information or materials, tasks were related to one another, work processes were coordinated, and subsets of members coordinated their work ( $1=$ not at all; $5=$ very great extent) (Wageman, 1995); goal congruence, measured with three items (alpha $=.82)$ which captured the extent to which collaborators shared the same vision, had similar reasons for participating, and shared the same incentives ( $1=$ not at all; $5=$ very great extent) (Puffer \& Meindl, 1992); and the pair-wise average shared past experience in the team, given evidence that prior work experience on past projects impacts film production (Taylor \& Greve, 2006; Harrison, Price \& Bell, 1998). Despite the arguments suggested by Ancona and Caldwell (1988) and Choi (2002) that the importance of external activities for team effectiveness may be proportional to the degree to which a team depends on and is depended on by external actors, none of these variables proved to be a statistically significant moderator of the relationship between external activity and effectiveness. This provides additional evidence that lack of permanence, fluidity, 
and volatility are important characteristics of new forms of work, in particular with implications for understanding processes vis-à-vis external constituents.

\section{DISCUSSION}

We began this research with a question: how does the external environment of teams influence the usefulness of team external activities? Our data lend us several provocative clues. First, external activity is not related to overall effectiveness when teams have stable roles and role incumbents (i.e. low fluidity) and when they operate in organizationally embedded contexts that are fairly simple and certain (i.e., low volatility). In contrast, when teams lack permanence, are highly fluid and volatile, then there is a distinct point of diminishing returns at about the mid point of our external activity scale. Extreme levels of external activity were detrimental to overall effectiveness. Even more striking, when teams are highly stable (i.e., when they have a high degree of permanence), external activity was negatively related to overall effectiveness. In these instances, the team may be subjected to attempts to dramatically sway or alter the product or service in a way that suits a particular external constituent, but may not be in the general best interest of the team's overall effectiveness. When this happens, team members may begin to feel that they are "selling out." Our interviews corroborated this quantitative evidence, with numerous examples of external activity that was later regretted by the film makers because the actions compromised the overall effectiveness of the final product, ranging from using a specific location for

filming due to tax incentives, changing the timeline or venue given weather constraints (i.e., accelerating a filming schedule to beat winter storms), using a specific distributor because it was attached to a screenplay, or changing the title and framing of the core narrative of the film to satisfy marketing agents. Such compromises are dramatic and palatable, but are not limited to the film industry. New product concepts are revised to meet investors' interests, relief efforts are rescheduled and relocated to address political and infrastructure concerns, service delivery models are adjusted to accommodate economic and technology windows of opportunity. These activities may be regrettable because although they may satisfy a limited set of constituent needs, they compromise the overall intent or vision of the product or service, and hence constitute a kind of "selling out." Yet, prior theorizing about team external environment and external activities such as these is insufficient for understanding these relationships, and hence our research extends theory in several ways.

\section{Theoretical Contributions}


First and foremost, prior research indicating that too much external activity in teams can be detrimental has primarily reasoned that this is true because external activities drain resources that would otherwise be used to ensure the management of internal team processes. While this logic offers part of the explanation, it doesn't incorporate an understanding of the manner in which features of the team's working environment may influence the usefulness of external activities. Here, we reasoned that external activities might also distract from the original vision or intent of the team, hence representing a sort of "selling out," and that this is likely to be true when there is turbulence in the external environment. This led us to conceptualize the external environment with greater precision and to analyze its effect on relationships between external activities and effectiveness.

Indeed, we found that the extent to which external activities are beneficial in teams depends on the degree to which there is a lack of permanence on the team, high fluidity of member roles, and volatility in the external environment. When a team has permanence, external constituents anticipate its on-going presence, allowing for patterns of external activities to be established in advance, routinized, and institutionalized. As a result, significant "mining for resources" (i.e., extensive additional external activity) is unlikely to produce performance gains. In fact, when a team has permanence, working to revise the patterns of external activity that have already been established may constitute a threat to the perceived legitimacy of the team, working to undermine the attainment of resources, support, or confidence of external constituents. We witnessed this occurring in observations of the teams in our study, and our interviews provided additional evidence that this mechanism accounts for at least part of the diminishing returns of external activities. Thus, rather than a direct effect on team outcomes, longevity of a team likely interacts with team behaviors (such as external activities) to change the strength of the effect of those behaviors on outcomes. To our knowledge, the mechanisms we propose for this relationship have not yet been empirically documented in the teams literature. Hence, our findings help lend an explanation for the failure to find a significant relationship between team longevity and outcomes such as innovation in recent meta-analyses (Hulsheger et al., 2009).

Likewise, when a team is fluid and expertise is constantly changing, focusing effort on understanding who has what expertise inside the team may be less beneficial than external activities which involve scanning the environment to locate knowledge and other resources outside the team. Such efforts are likely to yield higher returns than in those teams that have stable membership. Such a notion has been hinted at by others (e.g., 
(Majchrzak et al., 2007), but our study provides empirical grounding and additional theoretical framing for such observations.

Finally, with regard to external environmental volatility, we find that external activities have greater payoff when there is complexity (diversity of environmental features that must be addressed, Dess \& Beard, 1984) and uncertainty (inability to forecast in advance what performance conditions will exist, Waller, 1999). In these instances it is difficult to determine how best to interact with external constituents; hence, significant experimentation may be necessary in order to realize payoffs for effectiveness. This finding offers both empirical documentation, but also theoretical refinement to the ideas expressed by Choi (2002), who suggested that greater external activity may be necessary when constituents have diverse needs. We indicate this is true not only because those needs are different, but also difficult to predict.

Second, important boundary conditions for prior theories of teams, projects, or other social aggregates have seldom been incorporated into analyses as measured variables that represent potential moderators. As a result, it is unclear whether the relationships proposed in prior work hold true only in specific team types, or in all teams. We explicitly included three characteristics that vary among teams -- lack of permanence, fluidity, and volatility - in our analyses, and show that the relationship between team behaviors (i.e., external activity) and effectiveness vary dramatically depending on the extent to which the work is characterized by these features. Hence, we now know that external activity is most important for effectiveness when work efforts are extremely dynamic, fluid, and volatile. In fact, when these characteristics are not present then external activity is not a key driver of effectiveness, or can even be detrimental. For example, the impermanence that characterizes some teams requires that external activity be engaged in order to compensate for lack of familiarity with key constituents. In more permanent work structures, it is all the more likely that these same activities may constitute "selling out" and may be more harmful than helpful. Likewise, teams that are more openly exposed to changes in their environment because they are not insulated by the boundaries of a larger organizational context, and therefore cannot close themselves off to their external environment, have a particular need to be able to engage in external activities in order to access external sources of information, resources, and legitimacy. Such external activity in more stable, organizationally embedded teams may result in a misuse of critical organizational 
resources. Hence, fully understanding what it takes to successfully adapt to external challenges in teams requires a revision of existing theoretical models to incorporate these new features of teamwork.

Third, while contingency theorists have long noted that strategies must fit the environment in which they will be implemented (e.g., Gresov, 1989), adaptation to externalities has been viewed as a critical condition for effectiveness by institutional scholars (e.g., Meyer \& Rowan, 1977), and international strategic management theorists have argued that management of environmental interfaces are important in order to gain local legitimacy in environments that are more culturally and institutionally distinct from that of the participants (e.g., Xu, Pan \& Beamish, 2004), we extend these theories by further specifying the relationship between external activities and effectiveness in teams. We find that there is not a simple linear relationship between such activities and effectiveness but rather a non-monotonic relationship where too much external activity has adverse effects under certain conditions. In line with some prior theorizing at the business unit level (Gibson and Birkinshaw, 2004), we show that too much external activity may be detrimental to a team. Accordingly, as many different organizational forms strive to incorporate needs of external constituents in order to succeed and survive, it is vital to understand that external activity likely reaches a point of diminishing returns, beyond which it is not only unproductive but hazardous to venture.

Finally, we make a theoretical contribution to a second domain by expanding the concept of external activities in teams. Much of the prior work has examined teams that contain members who are all from the same organization, and the interactions they have outside their team, but still operating inside their single organization. Other research has examined teams embedded in a single organization and the information they gather from outside that organization, or the internal behavior they engage in to cope with changes that originate externally. But very little research has examined teams that have members who each represent different organizations, or who are independent contributors with no organizational affiliation. Such teams are increasingly common, and they frequently engage in interactions with external constituents with whom they are not formally employed, but on whom they rely for information, legitimacy and other resources. We further develop the distinctiveness of these interactions, as well as the idea that although they can be beneficial for the team, due to the cognitive and social demands they require, there is a point of diminishing returns.

\section{Limitations and Future Research}


In our examination of team external activity, we focused our efforts on understanding the influence of the external environment on the consequences of the extent of external activity. What we have not yet investigated is exactly how teams engage in this activity, nor have we examined changes in team external activity over the lifetime of their projects. Ancona (1990) found that in the short term, those teams that concentrated on ambassadorial and task-coordinator activity suffered from low levels of cohesion and high levels of disorganization; over time, as they satisfactorily interacted with their environment, internal team processes improved. For scouting teams, short-term cohesion and clarity of roles and goals eventually gave way to internal dissension as interaction with the external environment increased. Ancona and Caldwell (1992) demonstrated that while both ambassadorial and comprehensive strategies were related to achieving budget and schedules in the short term, only the comprehensive strategy was positively related to performance over time. This research suggests that certain activities may gain importance as the life of the team unfolds. That we are unable to address this issue is exacerbated by the fact that team members provided information at one point in time (i.e., at the end of their film projects), rather than at multiple points across the life of the project. Likewise, it will be important to understand exactly how and by whom external activities are carried out (Marrone, 2010). Future research might examine questions such as, When might it be most prudent for a team to use negotiating, repositioning, reframing, or altering behavior vis-à-vis external constituents outside the organization(s) with which members are affiliated? Are certain strategies better suited to different phases of collaborative efforts? We view examination of these issues using a longitudinal design with multiple measurement intervals as important extensions of our research with tremendous conceptual and practical value.

In addition, this study did not examine the impetus for external activity in great detail (i.e., what was the exact prompt for the external activity). For example, external activities enacted by the team may be engaged in to earn respect, maintain business, or impact external constituents' behavior or attitudes. Such activities may be engaged in due to technological challenges and opportunities such as technical failure or new technologies to incorporate, or they may be due to financial challenges and opportunities, such as lack of funding and increased resource needs or greater availability of funding due to new grants or revenue sources. External activities may be prompted by increased urgency of deadlines, delays, or perhaps relaxation of timelines, or they may be due to cultural and personnel challenges and opportunities such as differing values or ways of viewing the world, 
stereotypes, prejudice, lack of tolerance, bias, labor disputes, cultural development, or access to skilled workforce at lower wages. Zellmer-Bruhn (2003) found that interruptive events (e.g., coping with a structural change, redesigning the task, or changing authority) in teams prompted knowledge transfer activities (including those focused external to the team), and both knowledge transfer effort and interruptions were positively related to the acquisition of new work routines. It is likely that the optimal manner and degree of external activity will be dependent on the specific types of challenges and opportunities experienced, whether they be economic, political, or regulatory, technology-related, financial or time-related, or whether they pertain to the physical environment, or perhaps result from cultural and personnel challenges and opportunities.

It will also be important to understand whether external activities are engaged in as a result of a narrow set of external constituent demands or a broad set of needs, concerns, or requirements. If external activities meet only the needs of a narrow set of constituents and there is a lack of regard for a broader view of effectiveness, such activities may sway the product or service in an idiosyncratic way, such that the team is more likely to be perceived as "selling out." Another important extension of our research is to investigate each of the aspects of team external environment in greater depth. For example, Davis et al. found that the relationship between degree of formal organizational structure and firm performance was unexpectedly asymmetric, in that it is better to err on the side of too much structure, and that the different environmental volatility dimensions (i.e., velocity, complexity, ambiguity, and unpredictability) have unique effects on performance. Although their work is at the organizational level, it would be interesting and important to unpack multidimensional concepts such as volatility at the team level and better understand whether there are unique effects of each sub-dimension. Hence, we also encourage future research that investigates the relationship between the nature of changes in the environment or external demands, the manner in which a team engaged in external activity, and the effectiveness of these processes.

Finally, our approach of capturing a small number of respondents for each team across a large number of teams means that we have only a limited view of each. Given the temporary nature of many of the participants' involvement, reaching every member who contributed was impossible. This limitation is somewhat tempered by the fact that we have multiple sources of data about each film, from a variety of sources (i.e., surveys of team members, surveys of customers, archival data, interviews), which aligns with recent calls for multi-method 
approaches in developing new lines of inquiry (McDaniel and Gibson, 2012). That said, assessing perceptions of external activity across a greater number of participants is an important next step, and will likely require using means other than (or in addition to) surveys, such as longitudinal participant observation. This would no doubt provide vast insights into behavioral processes and outcomes. Conducting these investigations in settings such as new product development in the technology sector or in action teams would also ensure generalizability to a broad range of collaborative contexts.

\section{Conclusions}

We anticipate that external activity contributes to many important collaborative outcomes in addition to overall effectiveness, such as innovation, the collective process of incorporating knowledge into new methodologies, products and services (Nonaka \& Takeuchi, 1995). Beyond innovation, we have also observed that those teams that fail to engage in at least some degree of external activity may in fact fail to survive. Hence, we would argue that in many environments, external activity is necessary for the sustainability and longevity of the collaborative endeavor. Film making teams who cannot position their films such that they will be well received by the audiences that view them may find it impossible to get their films screened or distributed. An information technology consortium that doesn't negotiate well with investors when they show cultural proclivities toward certain technology trends may see their funding dry up and have to close up shop. Humanitarian aid workers that do not meet financial constraints or time urgency may see the aid go unused or misapplied. Yet, each of these types of collaborative endeavors faces a tenuous balancing act, in which creative vision must not succumb to "selling out." This serves to underscore the fundamental contingent nature of external activity, and provide insight into which teams will be most successful in the future, based on requirements of the environments in which they operate. 


\section{References}

Adler, P. S., \& Borys, B. 1996. Two types of bureaucracy: Enabling and coercive. Administrative Science Quarterly, 41: 61-89.

Adler, P. S., Goldoftas, B., \& Levine, D. I. 1999. Flexibility versus efficiency? A case study of model changeovers in the Toyota Production System. Organization Science, 10(1): 43-68.

Aiken, L. S. \& West, S. G. 1991. Multiple Regression: Testing and Interpreting Interactions. Thousand Oaks: Sage.

Alderfer, C. P. 1976. Boundary relations and organizational diagnosis. In M. Meltzer and F. Wickert (Eds.), Humanizing Organizational Behavior: 142-175. Springfield, IL: Charles C. Thomas.

Ancona, D. 1987. Groups in organizations : Extending laboratory models. In C. Hendrick (Ed.), Annual Review of Personality and Social Psychology: Group Processes and Intergroup Processes: 207-231. Beverly Hills, CA: Sage.

Ancona, D. G. 1990. Outward bound: Strategies for team survival in an organization. Academy of Management Journal, 33(2): 334-365.

Ancona, D. G. \& Bresman, H. 2007. X-Teams : How to Build Teams that Lead, Innovate, and Succeed. Boston, MA: Harvard Business School Press.

Ancona, D., Bresman, H., \& Kaeufer, K. 2002. The comparative advantage of X-Teams. MIT Sloan Management Review, 43 (3): 33-39.

Ancona, D. G. \& Caldwell, D. F. 1988. Beyond task and maintenance: Defining external functions in groups. Group and Organization Studies, 13: 468-494.

Ancona, D. G. \& Caldwell, D. F. 1992. Bridging the boundary: External activity and performance in organizational teams. Administrative Science Quarterly, 37: 634-665.

Ancona, D. G. \& Caldwell, D. F. 2000. Compose teams to assure successful boundary activity. In E. A. Locke, ed. Handbook of Principles of Organizational Behavior: Blackwell Publishers, Oxford, 199-210.

Bechky, B. A. 2006. Gaffers, gofers, and grips: Role-based coordination in temporary organizations. Organization Science, 17(1): 3-21.

Beng-Chong, L., \& Ployhart, R. E. 2004. Transformational leadership: Relations to the five-factor model and team performance in typical and maximum contexts. Journal of Applied Psychology, 89: 610-621.

Bigley, G. A. \& Roberts, K. H. 2001. The incident command system: High reliability organizing for complex and volatile task environments. Academy of Management Journal, 44: 1281-1300.

Bliese, P. 2000. Within-group agreement, non-independence, and reliability. K. Klein, S. Kozlowski eds., Multilevel Theory, Research, and Methods in Organizations: Jossey-Bass, San Francisco, 349-381.

Bresman, H. 2010. External learning activities and team performance: A multi-method field study. Organization Science, 21(2): 81-96.

Bunderson, J. S. \& Sutcliffe, K. M. 2003. Management team learning orientation and business unit performance. Journal of Applied Psychology, 88(3): 552-560.

Cannon-Bowers, J. A., Tannenbaum, S. I., Salas, E., \& Volpe, C. E. 1995. Defining competencies and 
establishing team training requirements. R. Guzzo, E. Salas eds., Team Effectiveness and Decision Making in Organizations: Jossey-Bass, San Francisco, 333-380.

Carson, S. J., Madhock, A., \& Wu, T. 2006. Uncertainty, opportunism and governance: The effects of volatility and ambiguity on formal and relational contracting. Academy of Management Journal, 49(5): 1058-1077.

Cattani, G. \& Ferriani, S. 2008. A core/periphery perspective on individual creative performance: Social networks and cinematic achievements in the Hollywood film industry. Administrative Science Quarterly, 19(6): 824844.

Choi, J.N. 2002. External activities and team effectiveness. Review and conceptual development. Small Group Research, 33(2): 181-208.

Clark, K. B. \& Fujimoto, T. 1987. Overlapping problem solving in product development. Working paper 87-048, Harvard University Graduate School of Business Administration, Cambridge, MA.

Cohen, S. G. \& Bailey, D. E. 1997. What makes teams work: Group effectiveness research from the shop floor to the executive suite. Journal of Management, 23: 239-290.

Colman, A. D. \& Bexton, W. H. (Eds.) 1975. Group Relations Reader. Sausalito, CA: GREX.

Davis, J. P., Eisenhardt, K. M. \& Bingham, C. B. 2007. Complexity theory, market dynamism, and the strategy of simple rules. Working paper, Stanford University, Stanford, CA.

Davis, J. P., Eisenhardt, K. M. \& Bingham, C. B. 2009. Optimal structure, market dynamism, and the strategy of simple rules. Administrative Science Quarterly, 54: 413-452.

Dawson, J. F., \& Richter, A. W. 2006. Probing three-way interactions in moderated multiple regression: Development and application of a slope difference test. Journal of Applied Psychology, 91, 917-926.

Dayan, M. \& Basarir, A. 2010. Antecedents and consequences of team reflexivity in new product development projects. Journal of Business and Industrial Marketing, 25(1): 19-29.

Dess, G. G., \& Beard, D. W. 1984. Dimensions of organizational task environment. Administrative Science Quarterly, 28: 274-291.

Dibble, R. 2010. Collaboration for the Common Good: An Examination of Internal and External Adjustment. Unpublisheddissertation, University of California, Irvine, Irvine, CA.

Dyer, L. \& Shafer, R. A. 2003. Dynamic organizations: Achieving marketplace and organizational agility with people. CAHRS Working Paper Series, Paper 27.

Ferriani, S., Corrado, R., \& Boschetti, C. 2005. Organizational learning under organizational impermanence: Collaborative ties in film project firms. Journal of Management Governance, 9: 257-285.

Galunic, D. C. \& Eisenhardt, K. M. 2001. Architectural innovation and modular corporate forms. Academy of Management Journal, 44(6): 1229-1249.

Ganzach, Y. 1997. Misleading interaction and curvilinear terms. Psychological Methods, 2: 235-247.

Gibson, C. B., \& Birkinshaw, J. 2004. The antecedents, consequences and mediating role of organizational ambidexterity. Academy of Management Journal, 47(2): 209-226. 
Gibson, C.B. and Dibble, R. 2008. Culture inside and out: Developing the collective capability to externally adjust. In S. Ang \& L. Van Dyne (Eds.), Advances in Cultural Intelligence, 221-240. New York: Sharpe.

Gibson, C. B., \& Gibbs, J. 2006. Unpacking the concept of virtuality: The effects of geographic dispersion, electronic dependence, dynamic structure, and national diversity on team innovation. Administrative Science Quarterly, 51(3): 451-495.

Gibson, C. B., Zellmer-Bruhn, M., \& Schwab, D. S. 2003. Team effectiveness in multinational organizations: Development and evaluation across contexts. Group and Organization Management, 28(4): 444-474.

Gladstein, D. L. 1984. Groups in context: A model of task group effectiveness. Administrative Science Quarterly, 29(4): 499-517.

Gresov, C. 1989. Exploring fit and misfit with multiple contingencies. Administrative Science Quarterly, 34: 431-453.

Haas, M. R. \& Hansen, M. T. 2005. When using knowledge can hurt performance: The value of organizational capabilities in a management consulting company. Strategic Management Journal, 26: 1-24.

Hackman, J. R. 2002. Leading Teams: Setting the Stage for Great Performances. Boston, MA: Harvard Business School Press.

Hale, J. E., Dulek, R.E., Hale, D.P.. 2005. Crisis response communication challenges. Journal of Business Communication, 42 112-134.

Harrison, D. A., Price, K. H., \& Bell, M. P. 1998. Beyond relational demography: Time and the effects of surface- and deep-level diversity on work group cohesion. Academy of Management Journal, 41(1): 96-107.

Hawley, A. 1968. Human ecology. D. L. Sills ed., International Encyclopedia of the Social Sciences: MacMillan, New York, 328-337.

Hoegl, M., Weinkauf, K., \& Gemuenden, H. G. 2004. Interteam coordination, project commitment, and teamwork in multi-team R\&D projects: A longitudinal study. Organization Science, 15(1): 38-55.

Hulsheger, U.R., Anderson, N., Salgado, J.F. 2009. Team-level predictors of innovation at work: A comprehensive meta-analysis spanning three decades of research. Journal of Applied Psychology, 95(5): 1128-1145.

Homans, G. 1950. The Human Group. New York: Harcourt Brace Jovanovich.

Ito, J. K. \& Peterson, R. B. 1986. Effects of task difficulty and interunit interdependence on information processing systems. Academy of Management Journal, 29(1): 139-149.

Katz, R. 1982. The effects of group longevity on project communication and performance. Administrative Science Quarterly, 27: 81-104.

Katz, R. \& Tushman, M. 1979. Communication patterns, project performance, and task characteristics: An empirical evaluation and integration in an R\&D setting. Organizational Behavior and Human Performance, 23: 139-162.

Kenny, D. A., \& LaVoie, L. 1985. Separating individual and group effects. Journal of Personality and Social Psychology, 48: 339-348.

Klein, K. J., \& Kozlowski, S. W. J. 2000. From micro to meso: Critical steps in conceptualizing and conducting multilevel research. Organizational Research Methods, 3(3): 211-236. 
Maitlis, S. \& Lawrence, T. B. 2007. Triggers and enablers of sensegiving in organizations. Academy of Management Journal, 50(1): 57-84.

Majchrzak, A., Jarvenpaa, S. L., \& Hollingshead, A. B. 2007. Coordinating expertise among emergent groups responding to disasters. Organization Science, 18(1): 147-161.

Marks, M. A., Zaccaro, S. J., \& Mathieu, J. E. 2000. Performance implications of leader briefings and teaminteraction training for team adaptation to novel environments. Journal of Applied Psychology, 85(5): 971-986.

Marrone, J. 2010. Team boundary spanning: A multi-level review of past research and proposals for the future. Journal of Management, 36(4): 911-938.

Mathieu, J.E., Marks, M.S., \& Zaccaro, S.J. 2001. Multi-team systems. N. Anderson, D. Ones, H. K. Sinangil, C. Viswesvaran, eds., International Handbook of Work and Organizational Psychology: Sage, London, 289-313.

McDaniel, D. and Gibson, C.B. (2012). Emergent ideas in emerging markets: The process of discovery in organizational research. In C. L. Wang, D. Ketchen, Jr., and D. B. (Eds.), Research Methodology in Strategy and Management. Emerald Press.

Meyer, J. W. \& Rowan, B. 1977. Institutionalized organizations: Formal structures as myth and ceremony. The American Journal of Sociology, 83(2): 340-363.

Moon, H., Hollenbeck, J. R., Humphrey, S. E., Ilgen, D. R., West, B., Ellis, A. P. J., \& Porter, C. 2004. Asymmetric adaptability: Dynamic team structures as one-way streets. Academy of Management Journal, 47(5): 681695.

Nonaka, I., \& Takeuchi, H. 1995. The Knowledge-creating Company: How Japanese Companies Create the Dynamics of Innovation. New York: Oxford University Press.

Okhuysen, G. A. 2001. Structuring change: Familiarity and formal interventions in problem-solving groups. Academy of Management Journal, 44(4): 794-808.

O'Leary, M. B., \& Cummings, J. N. 2007. The spatial, temporal, and configurational characteristics of geographic dispersion in teams. MIS Quarterly. (Forthcoming)

Palmer, I., Dunford, R., Rura-Polley, T., \& Baker, E. 2001. Changing forms of organizing: Dualities in using remote collaboration technology in film production. Journal of Organizational Change Management, 14(2): 190-207.

Pedhazur, E. J., \& Schmelkin, L. P. 1991. Measurement, Design, and Analysis: An Integrated Approach. Hillsdale, New Jersey: Erlbaum.

Puffer, S., \& Meindl, J.R. 1992. The congruence of motives and incentives in a voluntary organization. Journal of Organizational Behavior, 13(4): 425-435.

Sherif, M. 1966. In Common Predicament: Social Psychology of Intergroup Conflict and Cooperation. Boston: AddisonWesley.

Sinha, K. K., \& Van de Ven, A. H. 2005. Designing work within and between organizations. Organization Science, 16(4): 389-408.

Subramaniam, M., \& Youndt, M. A. 2005. The influence of intellectual capital on the types of innovation. Academy of Management Journal, 48(3): 450-463. 
Sutcliffe, K. M. 1994. What executives notice: Accurate perceptions in top management teams. Academy of Management Journal, 37: 1360-1378.

Taylor, A. \& Greve, H. R. 2006. Superman or the Fantastic Four? Knowledge combination and experience in innovative teams. Academy of Management Journal, 49(4): 723-740.

Tucker, A. L., Nembhard, I. M., \& Edmondson, A. C. 2007. Implementing new practices: An empirical study of organizational learning in hospital intensive care units. Management Science, 53: 894-907.

Van de Ven, A., H. \& Ferry, D. L. 1980. Measuring and Assessing Organizations. New York: Chichester.

Vera, D. \& Crossan, M. 2005. Improvisation and innovative performance in teams. Organization Science, 16(3): 203-224.

Von Hippel, E. 1990. Task partitioning: An innovation process variable. Research Policy, 19: 407-418.

Wageman, R. 1995. Interdependence and group effectiveness. Administrative Science Quarterly, 40(1): 145-180.

Waller, M. J. 1999. The timing of adaptive responses to non-routine events. Academy of Management Journal, 42: 127-137.

Wasko, J. 1994. Hollywood in the Information Age. Austin, TX: University of Texas Press.

Wong, S.-S. 2004. Distal and local group learning: Performance trade-offs and tensions. Organization Science, 15: 645-656.

Xu, D., Pan, Y., \& Beamish, P. W. 2004. The effect of regulative and normative distances on MNE ownership and expatriate strategies. Management International Review, 44: 285-307.

Zellmer-Bruhn, M. E. 2003. Interruptive evens and team knowledge acquisition. Management Science, 49(4): 514528.

Zenger, T. R., \& Hesterly, W. S. 1997. The disaggregation of corporations: Selective intervention, high-powered incentives, and molecular units. Organization Science, 8(3): 209-222. 

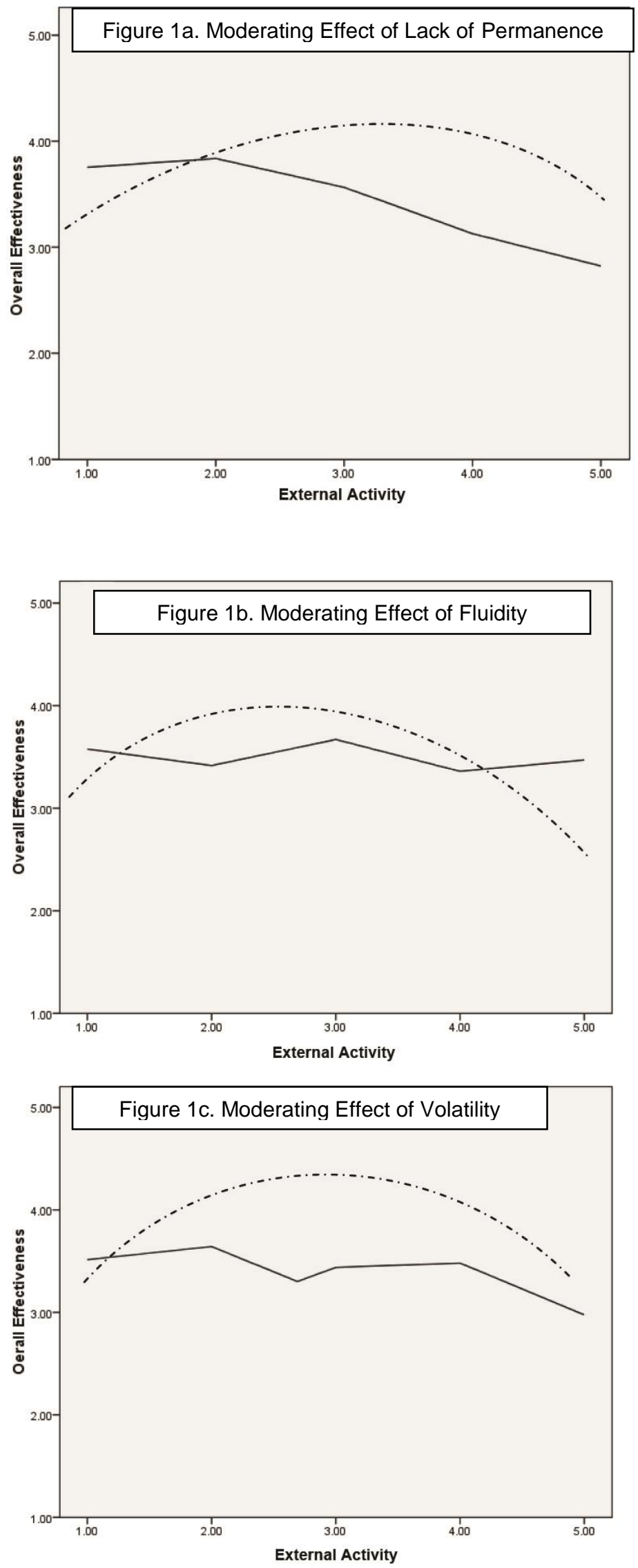

High permanence Low permanence

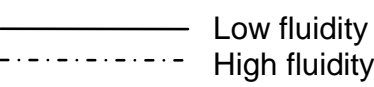

Low fluidity

High fluidity 
Table 1. Means, SD and Inter-correlations Among Variables in the Hypotheses

\begin{tabular}{|c|c|c|c|c|c|c|}
\hline Variable & Mean & S.D. & 1 & 2 & 3 & 4 \\
\hline 1. External Activity & 2.61 & 1.42 & & & & \\
\hline Lack of Permanence & 3.01 & 1.14 & .07 & & & \\
\hline Fluidity & 2.86 & .88 & .19 & .06 & & \\
\hline 4. Volatility & 2.06 & .91 & .03 & -.10 & .15 & \\
\hline Effectiveness & 3.50 & .61 & -.10 & .09 & -.04 & .20 \\
\hline
\end{tabular}

$\mathrm{N}=140$. Correlations with absolute value greater than .13 are significant at the .05 level. 
Table 2. Results of Moderated Regression Analysis for Overall Effectiveness

\begin{tabular}{|c|c|c|c|c|c|}
\hline Predictor variable ${ }^{*}$ & Step 1 & Step 2 & Step 3 & Step 4 & Step $4 a^{* *}$ \\
\hline Size of team & -.02 & -.05 & -.04 & .04 & .02 \\
\hline Number of raters & -.11 & -.08 & -.10 & -.06 & -.08 \\
\hline External activity & -.09 & $1.01^{\bullet}$ & $.87^{\bullet}$ & $.93^{\bullet}$ & $1.49^{\bullet}$ \\
\hline External activity squared & & $-1.13^{\bullet \bullet}$ & $-.97^{\bullet}$ & $-.93^{\bullet}$ & -1.19 \\
\hline Lack of permanence & & & .09 & .29 & .45 \\
\hline Fluidity & & & -.07 & -.06 & .32 \\
\hline Volatility & & & $.21^{\bullet}$ & -.02 & -.31 \\
\hline External activity $\mathrm{x}$ lack of permanence & & & & & -.71 \\
\hline External activity x fluidity & & & & & -.77 \\
\hline External activity $\mathrm{x}$ volatility & & & & & .84 \\
\hline External activity squared $\mathrm{x}$ lack of permanence & & & & $.85^{\bullet \bullet \bullet}$ & .10 \\
\hline External activity squared $\mathrm{x}$ fluidity & & & & $.35^{\bullet \bullet}$ & $.43^{\bullet \bullet}$ \\
\hline External activity squared $\mathrm{x}$ volatility & & & & $.48^{\bullet \bullet}$ & .11 \\
\hline$\Delta \mathrm{R}^{2}$ & & .05 & .05 & .14 & .06 \\
\hline$\Delta \mathrm{F}$ & & $7.61^{\bullet \bullet}$ & 2.29 & $8.25^{\bullet \bullet \bullet}$ & $3.60^{\bullet \bullet}$ \\
\hline$\Delta \mathrm{df}$ & & 1,135 & 3,132 & 3,129 & 3,126 \\
\hline Total $\mathrm{R}^{2}$ & .02 & .07 & .12 & .26 & .29 \\
\hline $\mathrm{F}$ & 1.07 & $2.74^{\bullet}$ & $2.59^{\bullet \bullet}$ & $4.59^{\bullet \bullet \bullet}$ & $3.89^{\bullet \bullet}$ \\
\hline D.f. & 3,139 & 4,139 & 7,139 & 10,139 & 13,139 \\
\hline
\end{tabular}

$\bullet \mathrm{p}<.05 ;{ }^{\bullet \bullet} \mathrm{p}<.01 ;{ }^{\bullet \bullet \bullet} \mathrm{p}<.001$.

$*$ Values are standardized regression weights. ${ }^{* *}$ Change statistics are for change from Step 3 to Step 4. 